\title{
Example of wave impact on a residential house
}

\author{
D. Wüthrich, M. Pfister \& A.J. Schleiss \\ Laboratoire de Constructions Hydrauliques (LCH), EPFL, Switzerland
}

\begin{abstract}
Waves impacting against structures can create damages and devastation. This topic regained interest after some recent catastrophic events and the present paper investigates the main phases of a wave impacting against a residential house commonly observed in areas subject to tsunami hazards. The project is based on an experimental approach and both dry bed surges and wet bed bores were tested. Through some visual observations and high speed cameras, important run-up heights in the vertical direction were observed for all configurations; these were more intense for wet bed bores. For the largest waves a full overflow of the structure was observed and the presence of the structure provoked a change of regime and the upstream propagation of a bore.
\end{abstract}

\section{INTRODUCTION}

In the past hydrodynamic waves such as dam-break waves, impulse waves and tsunamis were considered extremely rare events and most design codes do not present guidelines in this domain. Some recent catastrophic events with high casualties and significant damages showed the importance of wave-resistant houses as a mean to save people lives. On coastal areas around the Indian Ocean and at the mountains close to dam sights, most of the buildings do not exceed three floors, resulting into low structures characterised by a rectangular shape. Some previous relevant studies on wave impact against free standing structures were conducted by Cross (1967), Ramsden (1996), Arnason et al. (2009) and Nuori et al. (2010); it is also worth mentioning the Japanese contribution of Asakura et al. (2000) and Okada et al. (2005). Investigations on the behaviour of residential houses subject to wave impact were carried out by Thusyanthan and Madabhushi (2008), who tested a "tsunami resistant house" designed by Harvard design school in collaboration with MIT and compared it with a typical house in Sri Lanka. Wilson et al. (2009) and Van de Lindt (2009) tested a scaled wooden residential house in the US with both windows open and closed. The effect of porosity was tested by Lukkunaprasit et al. (2009). Chen et al. (2012) simulated the effect of overtopping waves and Shafiei Amraei et al. (2011) provided some visual observations of tsunami impact on some typical coastal structures. In the context of a broader research project investigating in a laboratory environment the structural loading during wave impact, the hydraulic behavior of the process is here described and discussed. When a building is hit by an incoming wave, the flow is 3-Dimensional, highly turbulent and many phenomena appear in a short period of time.
Some visual observations were carried out using highspeed cameras to provide a better understanding of the time development of these phenomena. Results showed some high splashes and important run-ups, provoking the overflow for the highest waves.

\section{EXPERIMENTAL SET UP}

For the present study a vertical release technique was used to produce both dry bed surges and wet bed bores; the same set-up was previously discussed and used by Wüthrich et al. (2016); similar techniques were used by Chanson et al. (2003), Meile (2007) and Rossetto et al. (2011). A known volume of water was released from an upper reservoir into a lower basin using three independent pipes with an internal diameter of $309 \mathrm{~mm}$. If a dam-break configuration is considered, different discharges resulted into various equivalent impoundment depths, leading to waves with different characteristics in terms of height and approaching velocities. The propagation of the wave took place in a smooth horizontal channel with a length of $14 \mathrm{~m}$ and a width of $1.4 \mathrm{~m}$, where the wave was followed in terms of velocity and height, using a UVP (Ultrasonic Velocity Profiler) and US (Ultrasonic distance Sensor) respectively.

The US probes were located at $x=2,10.1,12.1$, $13.1,13.35,13.6$ and $13.85 \mathrm{~m}$ from the beginning of the channel. The building was located at a distance of $14 \mathrm{~m}$ from the channel inlet, allowing sufficient time for the wave to fully develop and reach a quasisteady condition. The structure consisted of a $30 \mathrm{~cm}$ impervious aluminum cube with stiffness estimated to $k=2.2 \cdot 10^{8} \mathrm{~N} / \mathrm{m}$. Being the gravity effects predominant in this process, a Froude similitude with a scaling ratio of 1:30 was used and the structure corresponds 


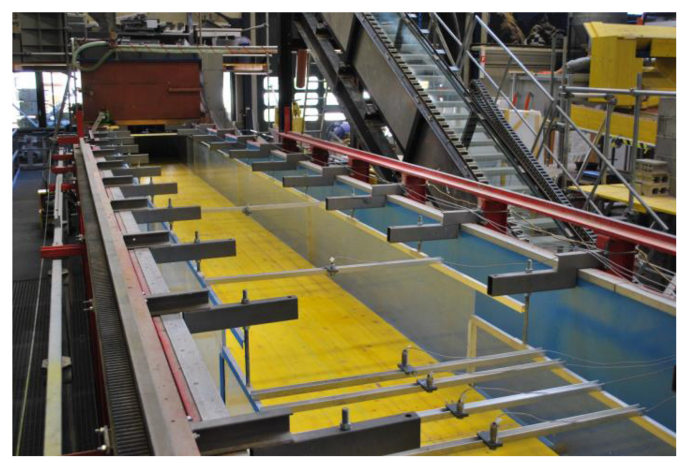

Figure 1. Experimental set-up and propagating channel.

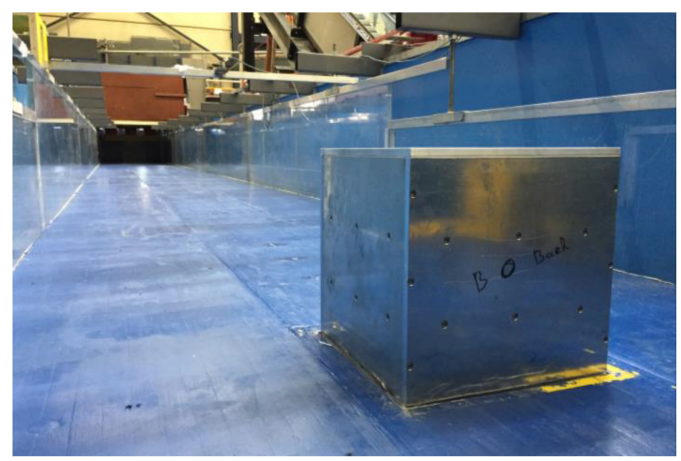

Figure 2. Channel with aluminum building $(H=0.3 \mathrm{~m})$.

to a building height of $9 \mathrm{~m}$ and to a wave ranging from 4.5 to $7.5 \mathrm{~m}$, which is consistent with real observations of tsunamis and buildings commonly found in coastal areas. Some scale effects are expected in the turbulent mixing process, where viscous effects are dominant and where a Reynolds similitude should be used. At the present time no systematic study on the scale effects on propagating bores was carried out (Docherty and Chanson 2012), however the viscous scaling effects were minimized using large Reynolds numbers $\left(\operatorname{Re}>10^{5}\right)$.

For all scenarios the maximum wave height $\left(h_{\max }\right)$ was lower than the building height $(H)$, however for the higher waves, some overflow was observed. For the channel, the blockage ratio was $\beta=B / H=4.6$. This value was not sufficient to fully avoid side effects, however in real life the effect of the walls could be justified with the presence of other buildings on the side. The front velocity $(V)$ was derived from the position of the front in time $(h>0.01 \mathrm{~m})$, measured with the US probes.

\section{EXPERIMENTAL RESULTS}

To obtain a complete insight of the process, both dry bed surges and wet bed bores with different wave heights and wavelengths were tested and analyzed. Longer waves better represent tsunamis, whereas impulse waves are characterized by lower periods and higher amplitudes. The tested scenarios are presented in Table 1 along with the main hydrodynamic properties of the produced waves.

\subsection{Dry bed surges}

Three surges on dry horizontal bed were tested; these were characterized by a thin front followed by a constant increase in water depth, until the maximum value was reached, then a constant decrease was observed. No aeration was noted in the propagating bore. Some secondary turbulence was observed on the surface of the surge, resulting from the internal turbulence of the flow. The waves were successfully compared with the theory developed by Ritter (1892) for a dam break scenario and three equivalent impoundment depths were used: $d_{0}=0.4 \mathrm{~m}$ ( 1 pipe $), d_{0}=0.6 \mathrm{~m}$ ( 2 pipes $)$ and $d_{0}=0.7 \mathrm{~m}$ ( 3 pipes), leading to wave heights and velocities presented in Table 1 (Wüthrich et al. 2016).

The smallest surge impacted against the structure with the lowest front velocity, producing a reduced amount of splashes. For this scenario, no overflow of the structure was observed.

When the tip hit the building some small vertical run up was measured, whose maximum height was slightly higher than the building (Figure 3a). Due to the transmission of momentum from the wave to the structure, the run-up moved backward, falling on the coming wave and producing a steady roller on the upstream side with air entrainment and high turbulence. The presence of the obstacle deviated the flow to both sides. The increasing discharge accentuated the deviation until the sides of the channel started having an influence (Figure $3 b$ ). As a consequence the wave height upstream of the building increased, the velocity decreased, leading to an important reduction of the Froude number. When the flow became subcritical a wave started propagating upstream. Behind the building the detachment of Von Kàrman vortexes were clearly observed.

For increasing impoundment depths the surges presented higher approaching velocities and higher vertical run-ups were observed, reaching some two times the height of the structure (Figure $3 \mathrm{~d}, \mathrm{~g}$ ). The run-up fell on top of the building; the latter was submerged by the coming wave. Similarly to the previous case, with the increasing discharge, the flow was deviated to the side, reducing the approaching velocity and producing a wave propagating in the upstream direction. The behavior of the highest surge was similar to the middle one, however the first seconds were characterized by a pulsating behavior, probably due to the interaction between the incoming wave and the reflection of the vertical run-up; the building was totally overflowed. During the decreasing phase of the wave, the water depth at building sight reduced and the behavior was similar to a quasi-steady flow around a squared obstacle. 
Table 1. Characteristics of the experimental tests carried out.

\begin{tabular}{llllll}
\hline & $\begin{array}{l}\text { Initial bed } \\
\text { condition }\end{array}$ & $\begin{array}{l}\text { Number } \\
\text { of pipes }\end{array}$ & $\begin{array}{l}\text { Equivalent impoundment } \\
\text { depth } d_{0}[\mathrm{~m}]\end{array}$ & $\begin{array}{l}\text { Maximum wave } \\
\text { height }[\mathrm{cm}]\end{array}$ & $\begin{array}{l}\text { Approaching } \\
\text { velocity }[\mathrm{m} / \mathrm{s}]\end{array}$ \\
\hline Surge 1 & Dry & 1 & 0.4 & 13.3 & 2.3 \\
Surge 2 & Dry & 2 & 0.6 & 17.8 & 3.1 \\
Surge 3 & Dry & 3 & 0.7 & 18.6 & 3.5 \\
Bore 1 & Wet, $h_{0}=3 \mathrm{~cm}$ & 3 & 0.7 & 25.4 & 2.8 \\
Bore 2 & Wet, $h_{0}=5 \mathrm{~cm}$ & 3 & 0.7 & 18.5 & 2.7 \\
Bore 3 & Wet, $h_{0}=5 \mathrm{~cm}$ & 1 & 0.4 & 1.9 & 1.9 \\
\hline
\end{tabular}

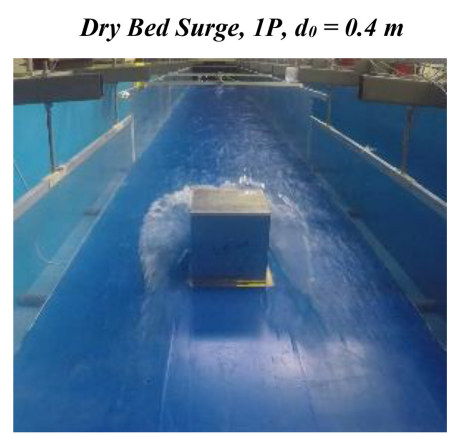

(a) $t=7 \mathrm{~s}$

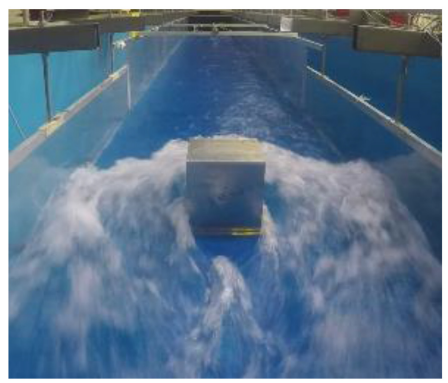

(b) $t=9 \mathrm{~s}$

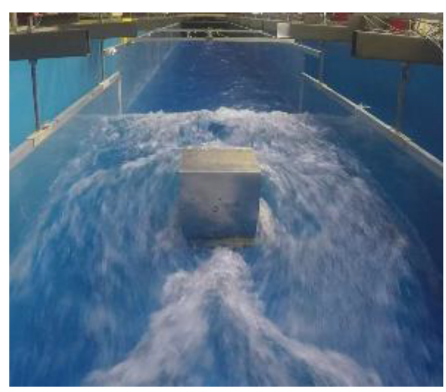

(c) $t=14 \mathrm{~s}$
Dry Bed Surge, $2 P, d_{0}=0.6 \mathrm{~m}$

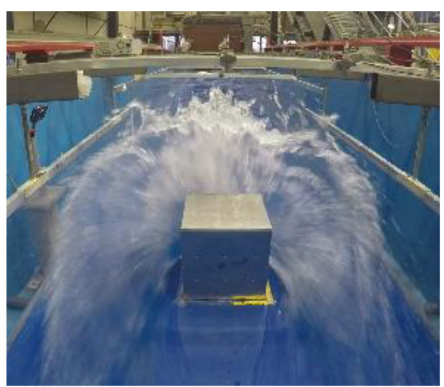

(d) $t=5 \mathrm{~s}$

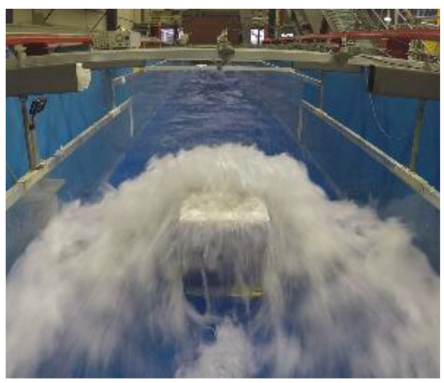

(e) $t=7 \mathrm{~s}$

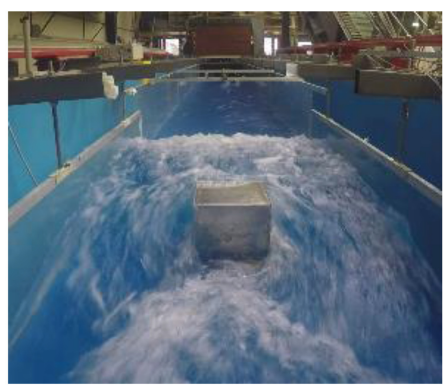

(f) $t=13 \mathrm{~s}$
Dry Bed Surge, $3 P, d_{0}=0.7 \mathrm{~m}$

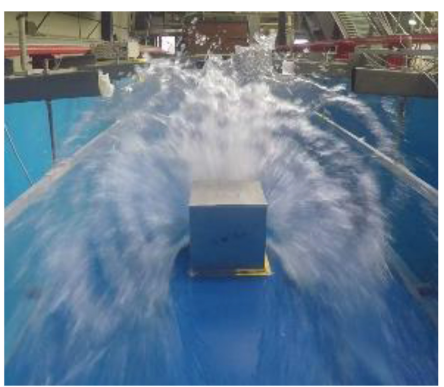

(g) $t=5 \mathrm{~s}$

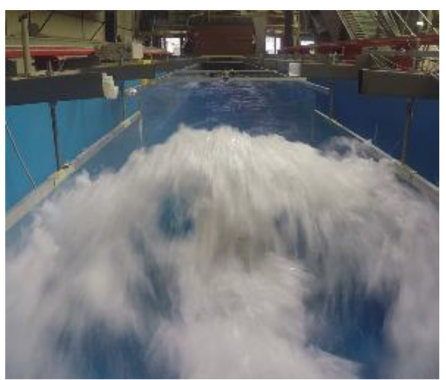

(h) $t=8 \mathrm{~s}$

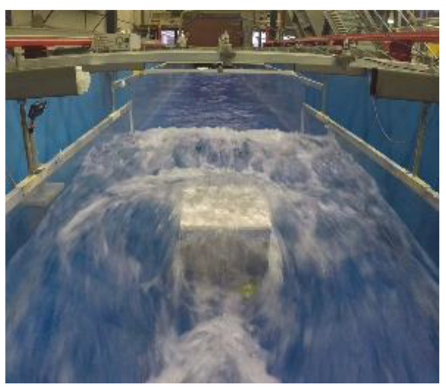

(j) $t=13 \mathrm{~s}$

Figure 3. Time lapse for the three tested surges: (a)-(c) $d_{0}=0.4 \mathrm{~m},(\mathrm{~d})-(\mathrm{f}) d_{0}=0.6 \mathrm{~m}$ and (g)-(j) $d_{0}=0.7 \mathrm{~m}$.

\subsection{Wet bed bores}

Waves propagating on an initial still water depth are commonly called bores and they have a completely different behavior than surges. These represent successive waves that propagates on the wet bed remaining from previous waves. Visually the bore appeared as a translating roller with high air entrainment, followed by a relatively constant water level; this configuration is consistent with the theory of Stoker (1957). The bores had lower velocities compared to dry bed surges and a steeper front for all configurations (Wüthrich et al. 2016).

During the impact against the structure all bores with the same impoundment depth $\left(d_{0}\right)$, independently from the initial still water depth $\left(h_{0}\right)$, showed a similar behavior. Three initial impoundment depths 
Bore, $3 P, d_{0}=0.7 \mathrm{~m}, h_{0}=3 \mathrm{~cm}$

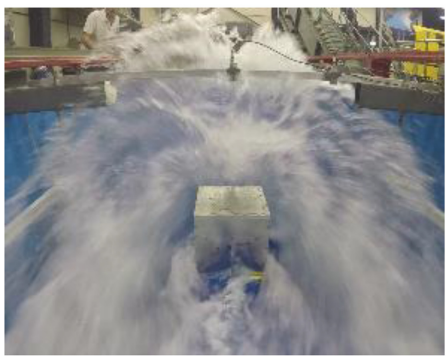

(a) $t=5 \mathrm{~s}$

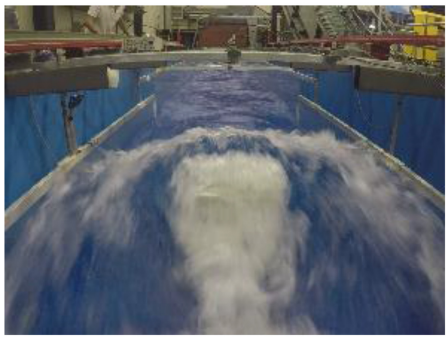

(b) $t=8 \mathrm{~s}$

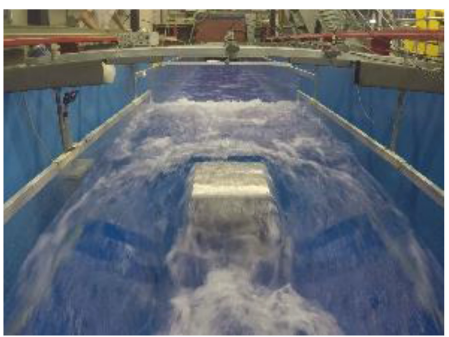

(c) $t=12 s$
Bore, $3 P, d_{0}=0.7 \mathrm{~m}, h_{0}=5 \mathrm{~cm}$

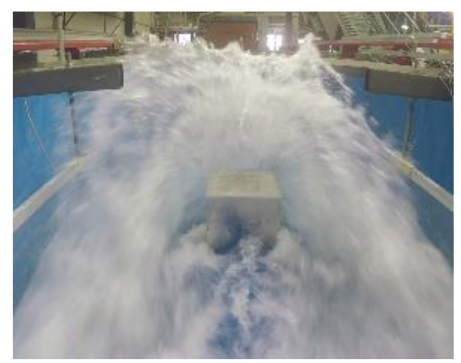

(d) $t=6 \mathrm{~s}$

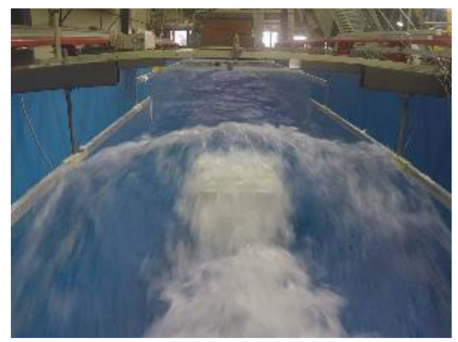

(e) $t=8 s$

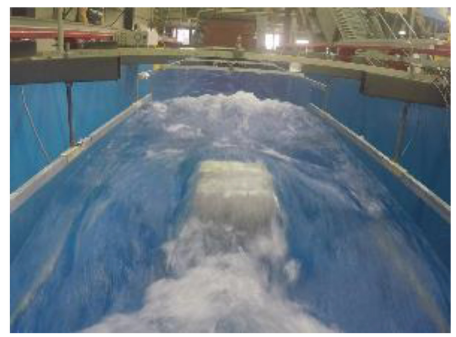

(f) $t=12 s$
Bore, $1 P, d_{0}=0.4 \mathrm{~m}, h_{0}=5 \mathrm{~cm}$

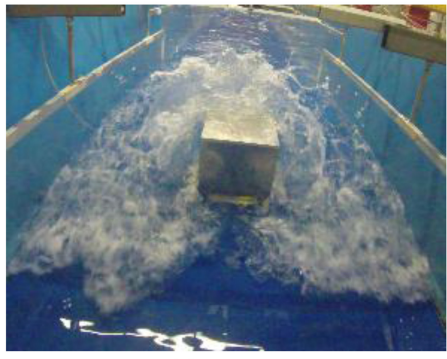

(g) $t=8 \mathrm{~s}$

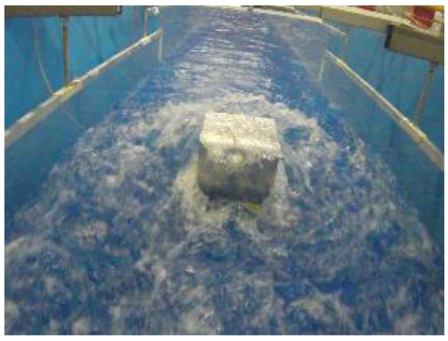

(h) $\mathrm{t}=10 \mathrm{~s}$

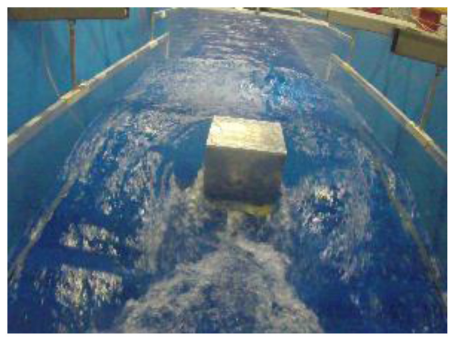

(j) $t=12 s$

Figure 4. Time lapse for the three testes bores: (a)-(c) $d_{0}=0.7 \mathrm{~m}, h_{0}=3 \mathrm{~cm}$ (d)-(f) $d_{0}=0.7 \mathrm{~m}, h_{0}=5 \mathrm{~cm}$ and (g)-(j) $d_{0}=0.4 \mathrm{~m}, h_{0}=5 \mathrm{~cm}$.

were tested, but only two are here presented $\left(h_{0}=\right.$ $3 \mathrm{~cm}, 5 \mathrm{~cm})$. Compared to the dry bed surges, for all bores higher vertical run-ups were observed (Figure 4a), probably due to the greater steepness of the front. For all configurations with three pipes (3P, $d_{0}=0.7 \mathrm{~m}$ ), the building is fully overflowed and submerged. For the bore produced with only one pipe (1P, $d_{0}=0.4 \mathrm{~m}$ ), splashes higher than the building height were observed, however the structure was not overflowed. Similarly to the sur-ges, the constriction due to presence of the building resulted into a change in the flow regime with waves propagating in the upstream direction. Like the previous case, the decreasing part of the wave was similar to a steady flow around a squared obstacle.

\section{DISCUSSION AND CONCLUSIONS}

Following the failure of a dam, a landslide into a lake or an offshore earthquake, a dam-break wave, an impulse wave or a tsunami are produced. Buildings located in the trajectory might be hit by this pro-pagating waves, leading to damages and devastation. The purpose of this study was to describe the main phenomena appearing during the impact of waves against an impervious $30 \times 30 \mathrm{~cm}$ aluminum cube, reproducing a residential house of $9 \times 9 \mathrm{~m}$ if a Froude scaling ratio of 1:30 is assumed. The project is based on an experimental approach and waves were produced using a vertical release technique. Given their different behavior, both dry bed surges and wet bed bores were tested. Highspeed cameras were used to gain a better insight and provide better support. Vi-sual observations proved that overall surges and bores with the same equivalent impoundment depths presented similar behaviors. For all scenarios the wave impact presented high splashes and some turbulent air entrainment on the upstream side of the building. In general bores showed higher splashes, probably due to their steeper front. The presence of the building provoked a constriction, with a decrease in flow velocity and an increase of the water level. The combination of these effects lead to a change in the flow regime and a propagation of a bore in the upstream direction. For all waves produced using three pipes $\left(d_{0}=0.7 \mathrm{~m}\right)$ an overflow was 
observed and the structure was fully submerged. For the smallest waves the structure was not overflowed and the roof could be used as a vertical shelter in case of tsunami alert. As expected from literature, the visual observations proved a substantial difference in behavior between bores and surges. The same difference was observed during the building impact, however at this early stage it is premature to decide which type represents the more critical scenario. Further investigations are necessary and the measurements of impact forces essential to decide which type should be used to design wave-resistant houses. Furthermore, these findings only apply to impervious structures; the presence of opening such as windows and doors could completely change the behavior of the flow.

\section{ACKNOWLEDGMENT}

The support of the Swiss National Science Foundation (SNSF), grant 200021_149112/1 is acknowledged.

\section{NOTATION}

$B$

channel width $[\mathrm{m}]$

$d_{0} \quad$ initial equivalent impoundment depth [m]

$H \quad$ building height and width [m]

$h \quad$ wave height [m]

$h_{0} \quad$ initial water depth in the channel [m]

$h_{\max } \quad$ maximum wave height $[\mathrm{m}]$

$k$ building stiffness [N/m]

$t \quad$ time [s]

$x \quad$ longitudinal direction of the channel [m]

$\beta \quad$ blockage ratio

\section{REFERENCES}

Arnason H., Petroff C., and Yeh H. 2009. Tsunami bore impingement onto a vertical column. Journal of Disaster Research, 4(6):391-403.

Asakura R., Iwase K., Ikeya T., Takao M., Kaneto T., Fujii N., and Omori M. 2000. An experimental study on wave force acting on on-shore structures due to overflowing tsunamis. Proceedings of Coastal Engineering JSCE, 47:911-915.

Chanson H., Aoki S., and Maruyama M. 2002. Unsteady air bubble entrainment and detrainment at a plunging breaker: dominant time scales and similarity of water level variations. Coastal Engineering, 46(2):139-157.
Chen X., Hofland B., Altomare C., Suzuki T., and Uijttewaal W. 2015. Forces on a vertical wall on a dike crest due to overtopping flow. Coastal Engineering, 95:94-104.

Cross R. 1967. Tsunami surge forces. Journal of the Waterways and Harbors Division, 93(4):201-231.

Docherty N.J and Chanson H. 2012. Physical Modeling of Unsteady Turbulence in Breaking Tidal Bores. Journal of Hydraulic Engineering, 138(5):412-419

Lukkunaprasit P., Ruangrassamee A., and Thanasisathit N. 2009. Tsunami loading on buildings with openings. Science of Tsunami Hazards, 28(5):303.

Meile T. 2007. Influence of macro-roughness of walls on steady and unsteady flow in a channel. Ph.D. Thesis, EPFL-LCH, Lausanne Switzerland, 414 pages.

Nouri Y., Nistor I., Palermo D., and Cornett A. 2010. Experimental investigation of tsunami impact on free standing structures. Coastal Engineering Journal, 52(01):43-70.

Okada T., Sugano T., Ishikawa T., Ohgi T., Takai S., and Hamabe C. 2005. Structural design method of buildings for tsunami resistance. Building Technology Research Institute, Building Centre for Japan, 15.

Ramsden J. 1996. Forces on a vertical wall due to long waves, bores, and dry-bed surges. Journal of waterway, port, coastal, and ocean engineering, 122(3):134-141.

Ritter A. 1892. Die Fortpflanzung der Wasserwellen. Zeitschrift Verein Deutscher Ingenieure, 36, 33, 947-954

Rossetto T., Allsop W., Charvet I., and Robinson D. 2011. Physical modelling of tsunami using a new pneumatic wave generator. Coastal Engineering, 58(6):517-527.

Shafiei Amraei SR., Melville B.W., Shamseldin A.Y., Burridge B. and Hogan A. 2011. Tsunami impact on Coastal Structures. 34th IAHR World Congress - Balance und Uncertainty, Brisbane, Australia, 26 June-1 July

Stoker J.J. 1957. Water Waves: The Mathematical Theory with Applications. Intersciences, 567 pages

Thusyanthan N. I., \& Gopal Madabhushi S. P. 2008. Tsunami wave loading on coastal houses: a model approach. Proceedings of the Institution of Civil Engineers-Civil Engineering, 161(2):77-86.

Van de Lindt J., Graettinger A., Gupta R., Skaggs T., Pryor S., and Fridley K. 2007. Performance of wood-frame structures during Hurricane Katrina. Journal of Performance of Constructed Facilities, 21(2):108-116.

Wilson J., Gupta R., Van de Lindt J., Clauson M., and Garcia R. 2009. Behavior of a one-sixth scale woodframed residential structure under wave loading. Journal of Performance of Constructed Facilities, 23(5):336-345.

Wüthrich D., Nistor I., Pfister M. and Schleiss A.J. 2016. Experimental generation of tsunami-like waves. Proceedings of Coastal Structures. Boston, MA, USA. 9-11 September (under publication). 